\title{
Acute upper airway disease in children with the omicron (B.1.1.529) variant of SARS-CoV- 2: a report from the National COVID Cohort Collaborative (N3C)
}

Blake Martin, $\mathrm{MD}^{1}$, Peter E. DeWitt, $\mathrm{PhD}^{2}$, Seth Russell, $\mathrm{MS}^{2}$, L. Nelson Sanchez-Pinto, MD, $\mathrm{MBI}^{3}$, Melissa A. Haendel, $\mathrm{PhD}^{4}$, Richard Moffitt, $\mathrm{PhD}^{5}$, Tellen D. Bennett, MD, MS ${ }^{1,2}$

\section{Affiliations:}

1. Section of Critical Care Medicine, Department of Pediatrics, University of Colorado School of Medicine, University of Colorado, Aurora, CO, USA

2. Section of Informatics and Data Science, Department of Pediatrics, University of Colorado School of Medicine, University of Colorado, Aurora, CO, USA

3. Division of Critical Care, Department of Pediatrics, Northwestern University Feinberg School of Medicine, Chicago, IL, USA

4. Department of Biochemistry and Molecular Genetics and the Center for Health Artificial Intelligence, University of Colorado School of Medicine, University of Colorado, Aurora, CO, USA

5. Department of Biomedical Informatics, Stony Brook University, Stony Brook, NY, USA

\author{
Corresponding Author: \\ Blake Martin, MD \\ Section of Critical Care Medicine \\ Department of Pediatrics \\ University of Colorado School of Medicine \\ 13123 E. 16th Ave \\ Aurora, CO 80045 \\ (303) 918-8655 \\ blake.martin@cuanschutz.edu
}


medRxiv preprint doi: https://doi.org/10.1101/2022.01.27.22269865; this version posted January 30, 2022. The copyright holder for this preprint

(which was not certified by peer review) is the author/funder, who has granted medRxiv a license to display the preprint in perpetuity.

It is made available under a CC-BY-NC-ND 4.0 International license.

\begin{abstract}
Background: Reports of SARS-CoV-2 causing laryngotracheobronchitis (commonly known as croup) have been limited to small case series. Early reports suggest the Omicron (B.1.1.529) strain of SARSCoV-2 (the dominant circulating US strain since the week of 12/25/2021) replicates more efficiently in the conducting airways. This may increase the risk of a croup phenotype in children as they have smaller airway calibers.
\end{abstract}

Methods: Description of the incidence, change over time, and characteristics of children with SARSCoV-2 and upper airway infection (UAI) diagnoses within the National COVID Cohort Collaborative (N3C) before and during the rise of the Omicron variant. We compare the demographics, comorbidities, and clinical outcomes of hospitalized SARS-CoV-2 positive children with and without UAI.

Results: SARS-CoV-2 positive UAI cases increased to the highest number per month $(\mathrm{N}=170)$ in December 2021 as the Omicron variant became dominant. Of 15,806 hospitalized children with SARSCoV-2, $1.5 \%(234 / 15,806)$ had an UAI diagnosis. Those with UAI were more likely to be male, younger, white, have asthma and develop severe disease as compared to those without UAI.

Conclusions: Pediatric acute UAI cases have increased during the Omicron variant surge with many developing severe disease. Improved understanding of this emerging clinical phenotype could aid in therapeutic decision-making and healthcare resource planning. 


\section{Introduction}

SARS-CoV-2 can cause severe pediatric disease including acute COVID-19 and multisystem inflammatory syndrome in children (MIS-C) ${ }^{1}$. Published reports of SARS-CoV-2 causing laryngotracheobronchitis (commonly known as "croup"), however, have been limited to small case series $^{2}$. Other coronaviruses (e.g. type NL63) are known to cause croup.

The Omicron (B.1.1.529) strain of SARS-CoV-2 became dominant in the U.S. during the week of $12 / 25 / 2021^{3}$. Early reports suggest Omicron may cause lower severity disease than the Delta variant ${ }^{4}$. This may be because Omicron replicates less efficiently in lung parenchyma and more efficiently in the conducting airways ${ }^{5}$. However, these mechanistic hypotheses have not been confirmed.

Young children are especially vulnerable to acute upper airway infection (UAI) because their airways are small and relatively collapsible. Inflammation from UAI can rapidly decrease air flow. Accordingly, croup is classically an early childhood disease. We conducted this retrospective cohort study to determine if acute UAI is more common as Omicron has become the dominant U.S. SARS-CoV-2 variant.

\section{Methods}

We leveraged the National COVID Cohort Collaborative (N3C) ${ }^{6}$ and a pipeline we built for a NIHfunded pediatric COVID-19 dashboard (https://covid.cd2h.org/pediatrics-dashboard/) to conduct this study. Among all children in N3C <19-years-old with a positive SARS-CoV-2 test (polymerase chain reaction, antigen, or antibody), we identified those with a croup or tracheitis diagnosis. We included bacterial tracheitis because it can be difficult to distinguish from $\square-$ and can be a complication of $\square-$ viral croup. We compared groups using chi-square and Fisher exact tests for categorical variables and Mood's Median test and t-tests for continuous variables. The N3C Data Enclave, data transfer from sites to $\mathrm{N} 3 \mathrm{C}$, and this analysis were approved under separate institutional review board protocols as documented elsewhere ${ }^{1}$.

\section{Results}

SARS-CoV-2 positive UAI cases have increased as the Omicron variant has become dominant (Figure 1). During December 2021, we observed the largest monthly number thus far of hospitalized ( $\mathrm{N}=32)$ and non-hospitalized ( $\mathrm{N}=138)$ SARS-CoV-2 positive UAI cases. Of December 2021 hospitalizations, 2.5\% (32/1302) had UAI. Overall, the 1/13/2022 N3C data release contains 15,806 hospitalized SARS-CoV-2 positive children, of whom $1.5 \%(234 / 15,806)$ had UAI (Table 1). Compared to those without UAI, those with UAI were more likely to be male $(59.8 \%$ versus $50.4 \%, \mathrm{p}=0.003)$, younger ( 2.4 versus 10.1 years, $\mathrm{p}<0.001)$, white $(54.7 \%$ versus $43.3 \%, \mathrm{p}=0.02)$, and have asthma ( $15 \%$ versus $10 \%, \mathrm{p}=0.02)$. Children with UAI experienced severe disease (invasive ventilation, vasopressors, ECMO, or mortality) more often compared to children without UAI $(31.6 \%$ versus $13.5 \%$, $\mathrm{p}<0.001)$.

\section{Discussion}

Overall, pediatric acute UAI has increased during the Omicron variant surge. Nearly a third of affected children develop severe disease. This observed clinical phenotype of pediatric infection by the Omicron variant appears to confirm recent mechanistic reports.

A limitation of this analysis is that diagnosis codes will only be present for completed hospitalizations in $\mathrm{N} 3 \mathrm{C}$; children who are still hospitalized are not represented. 
Although many children with acute UAI are managed as outpatients, those with severe croup and/or tracheitis are at risk of cardiac arrest from rapid-onset upper airway obstruction. They may require therapies typically provided in intensive care units including frequent administration of nebulized racemic epinephrine, helium/oxygen mixtures, and intubation. While SARS-CoV-2 pediatric UAI rates are not overwhelmingly high, understanding this new clinical phenotype is important to health systems under severe strain. Anticipation of the potential for acute upper airway obstruction may guide therapeutic decision-making and hospital planning for available equipment and personnel.

\section{Acknowledgements}

The N3C was funded by NCATS grant number U24 TR002306 and other support as documented at https://covid.cd2h.org/acknowledgements. This analysis was supported by NICHD grant number R01HD105939-01S1.

\section{References:}

1. Martin B, DeWitt PE, Russell S, et al. (in press). Children with SARS-CoV-2 in the National COVID Cohort Collaborative (N3C). JAMA Netw Open. 2022.

2. Venn AMR, Schmidt JM, Mullan PC. Pediatric croup with COVID-19. Am J Emerg Med. 2021;43:287 e281-287 e283.

3. Centers for Disease Control and Prevention. COVID Data Tracker: Variant Proportions. https://covid.cdc.gov/covid-data-tracker/\#variant-proportions. Published 2022. Accessed Jan 18, 2022.

4. Ulloa AC, Buchan SA, Daneman N, Brown KA. Early estimates of SARS-CoV-2 Omicron variant severity based on a matched cohort study, Ontario, Canada. medRxiv. 2021.

5. Chan MC, Hui KP, Ho J, et al. SARS-CoV-2 Omicron variant replication in human respiratory tract ex vivo. Dec 2021, PREPRINT (Version 1) available at Research Square https://doi.org/10.21203/rs.3.rs$1189219 / \mathrm{v} 1$

6. Haendel MA, Chute CG, Bennett TD, et al. The National COVID Cohort Collaborative (N3C): rationale, design, infrastructure, and deployment. Journal of the American Medical Informatics Association. 2021;28(3):427-443. 


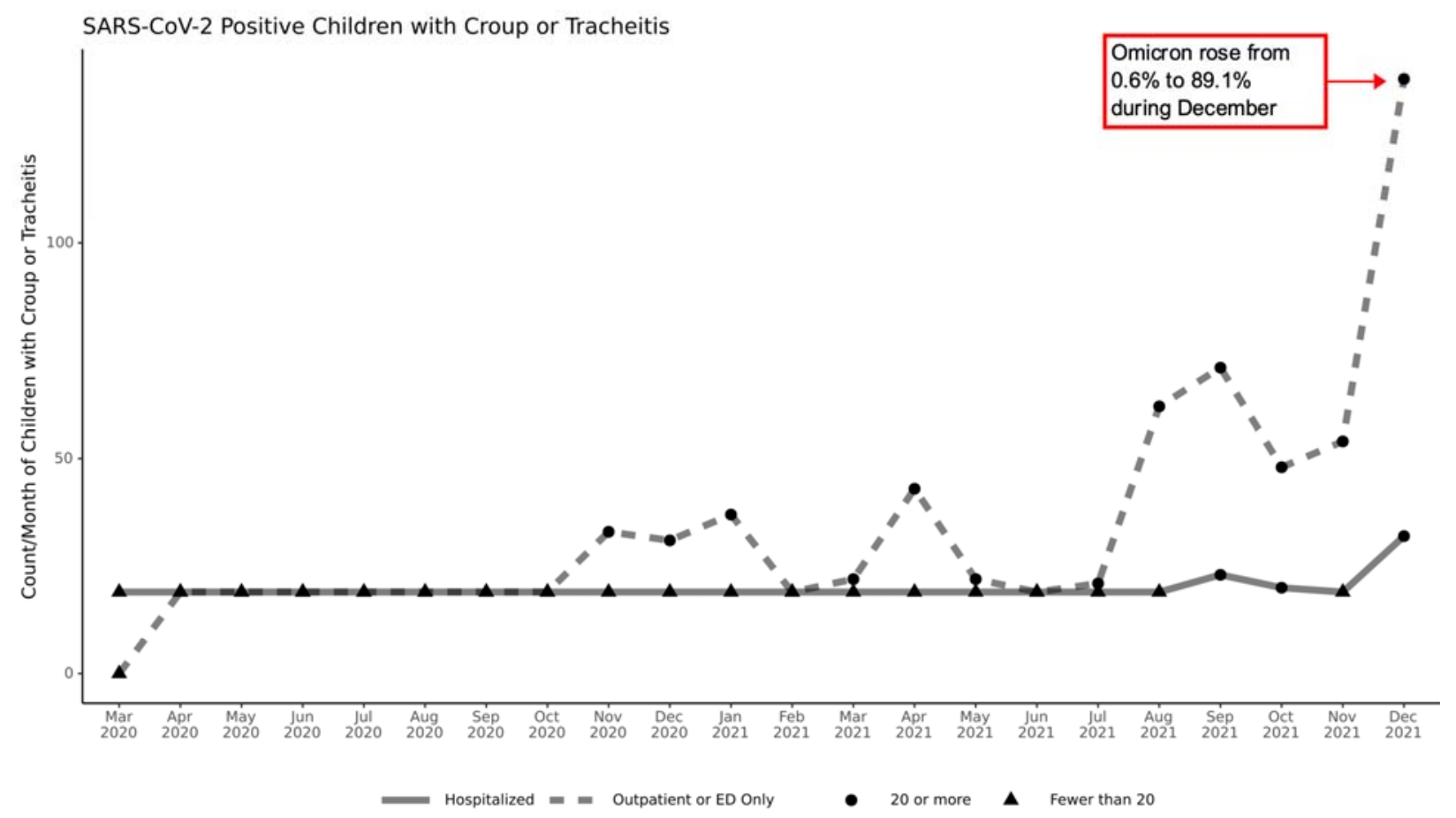

Figure 1: This figure shows the count per month of inpatient (solid line) and outpatient/Emergency Department (dotted line) encounters with a diagnosis of croup or tracheitis for children less than 19-yearsold with positive SARS-CoV-2 tests in the National COVID Cohort Collaborative (N3C) January 13th, 2022 data release. The percentage of SARS-CoV-2 samples found to be the Omicron strain is from the U.S. Centers for Disease Control COVID Data Tracker, available at https://covid.cdc.gov/covid-datatracker/\#variant-proportions and accessed January 19, 2022. Triangles represent individual counts 1-19 that are censored as per N3C policy and shown as $n=19$ in the figure. 


\section{Children with COVID-19 with and without croup or tracheitis}

\begin{tabular}{|c|c|c|c|}
\hline Variable & $\begin{array}{l}\text { No Croup } \\
\text { or Tracheitis } \\
(\mathbf{N}=\mathbf{1 5 , 5 7 2})\end{array}$ & $\begin{array}{l}\text { Croup or Tracheitis } \\
\qquad(\mathbf{N}=\mathbf{2 3 4})\end{array}$ & p value \\
\hline Gender & & & $p=0.003$ \\
\hline Male & $7,850 *(50.4 \%)$ & $140 *(59.8 \%)$ & \\
\hline Female & $7,720 *(49.6 \%)$ & $90 *(38.5 \%)$ & \\
\hline Other & $<20(<0.1 \%)$ & $<20(<8.5 \%)$ & \\
\hline \multicolumn{4}{|l|}{ Age } \\
\hline Age in years: mean (SD) & $9.4(6.6)$ & $4.3(4.6)$ & $\mathrm{p}<0.001$ \\
\hline Age in years: median (IQR) & $10.1(2.3,15.7)$ & $2.4(1.3,5.6)$ & $\mathrm{p}<0.001$ \\
\hline Ethnicity & & & $\mathrm{p}=0.25$ \\
\hline Hispanic or Latino & $4,058(26.1 \%)$ & $50 *(21.4 \%)$ & \\
\hline Not Hispanic or Latino & $10,195(65.5 \%)$ & $170 *(72.6 \%)$ & \\
\hline Missing/Unknown & $1,319(8.5 \%)$ & $<20(<8.5 \%)$ & \\
\hline Race & & & $\mathbf{p}=\mathbf{0 . 0 2}$ \\
\hline Asian & $331(2.1 \%)$ & $<20(<8.5 \%)$ & \\
\hline Black or African American & $4,169(26.8 \%)$ & $44(18.8 \%)$ & \\
\hline Native Hawaiian or Other Pacific Islander & $54(0.3 \%)$ & $<20(<8.5 \%)$ & \\
\hline White & $6,741(43.3 \%)$ & $128(54.7 \%)$ & \\
\hline Other & $3,837(24.6 \%)$ & $52(22.2 \%)$ & \\
\hline Missing/Unknown & $440(2.8 \%)$ & $<20(<8.5 \%)$ & \\
\hline \multicolumn{4}{|l|}{ Comorbidities } \\
\hline Known BMIf & $6,606(42.4 \%)$ & $69(29.5 \%)$ & $\mathrm{p}<0.001$ \\
\hline Obese $(\geq 95$ th percentile $) \dagger$ & $2,095(31.7 \%)$ & $21(30.4 \%)$ & $\mathrm{p}=0.90$ \\
\hline Diabetes Mellitus (Types I \& II) & $389(2.5 \%)$ & $<20(<8.5 \%)$ & $\mathrm{p}=0.13$ \\
\hline Asthma & $1,551(10.0 \%)$ & $35(15.0 \%)$ & $p=0.02$ \\
\hline \multicolumn{4}{|l|}{ Medications Received } \\
\hline Dexamethasone & $880(5.7 \%)$ & $81(34.6 \%)$ & $\mathrm{p}<0.001$ \\
\hline Systemic Antibiotic & $4,835(31.0 \%)$ & $88(37.6 \%)$ & $\mathbf{p}=\mathbf{0 . 0 3}$ \\
\hline COVID Severity & & & $\mathrm{p}<0.001$ \\
\hline Moderate & $13,464(86.5 \%)$ & $160(68.4 \%)$ & \\
\hline Severe & $2,108(13.5 \%)$ & $74(31.6 \%)$ & \\
\hline
\end{tabular}

Table 1: This table shows demographic and clinical characteristics for children less than 19 years old with positive SARS-CoV-2 tests, with and without a diagnosis of croup or tracheitis. Per N3C policy, cells with less than 20 patients are reported as " $<20(\mathrm{x} \%)$ " where $\mathrm{x}$ is the percentage if $\mathrm{n}=20$. Abbreviations: $\mathrm{BMI}=$ body mass index, $\mathrm{IQR}=$ interquartile range, $\mathrm{SD}=$ standard deviation * Result rounded to the nearest 10 to avoid exposure of cell values under 20 (as per N3C policy) f Number of patients $\geq 2$-years-old for whom a BMI measurement was available $\dagger$ Obesity determined as per the Centers for Disease Control and Prevention (CDC) guidelines (https://www.cdc.gov/obesity/childhood/defining.html) with obesity defined as any child $\geq 2$-years-old 
medRxiv preprint doi: https://doi.org/10.1101/2022.01.27.22269865; this version posted January 30, 2022. The copyright holder for this preprint (which was not certified by peer review) is the author/funder, who has granted medRxiv a license to display the preprint in perpetuity. It is made available under a CC-BY-NC-ND 4.0 International license.

with a BMI $\geq 95$ th percentile for age and sex. Percentages reported in the "Obese ( $\geq 95$ th percentile)" row represent the percent of patients with a known BMI value who had a BMI greater than 95th percentile for age and sex. 